\title{
A comprehensive list of asthmagens to inform health interventions in the Australian workplace
}

\author{
Julie Crewe, ${ }^{1}$ Renee Carey, ${ }^{1}$ Deborah Glass, ${ }^{2}$ Susan Peters, ${ }^{3}$ Michael J. Abramson, ${ }^{2}$ Geza Benke, ${ }^{2}$ Alison Reid, ${ }^{1}$ \\ Tim Driscoll, ${ }^{4}$ Lin Fritschi ${ }^{1}$
}

$B$ etween 1,000 and 3,000 new cases of asthma in Australia annually could be attributed to workplace exposures. ${ }^{1}$ However, precise information on the nature and extent of occupational asthma (OA) in Australia to inform policy development is not currently available. Estimates of adultonset asthma cases that can be attributed to occupational exposures range from $9 \%$ to $17 \%$ in Australia. ${ }^{1-3}$ Internationally, a study of more than 41,000 workers in 19 broad occupational groups in the US reported a prevalence of OA of $8.1 \%(95 \% \mathrm{Cl}$ 7.8- 8.5\%). When compared to a reference group of administration workers, the highest prevalence ratios (PR) were reported for health workers (PR 1.5, 95\% Cl 1.2-1.9) and teachers (PR 1.3, 95\% Cl 1.1-1.6). ${ }^{4}$

Australia does not have a national notification scheme for OA. A small number ( $\mathrm{n}=292$ since 2008) of cases are reported to the statebased Surveillance of Australian Workplace Respiratory Events (SABRE) in New South Wales, Victoria and Tasmania together., Similarly, only a few cases are compensated through workers' compensation schemes; 15 claims per million employees over the most recent seven-year period. ${ }^{7}$

The first step in understanding occupational asthma in Australia is to understand the potential causes. There is no body or document that lists confirmed or reported asthmagens encountered in Australia. While there are a great number of confirmed asthmagens that have been linked to $O A$, there is no over-arching internationally established and peer-reviewed list of occupational asthmagens. Although various

\begin{abstract}
Objective: To develop a comprehensive list of asthmagens which may occur in occupational settings in Australia.

Methods: Potential asthmagens considered for this list were identified through work health and safety classification databases in Australia and through lists developed by professional associations in other countries. Inclusion criteria were: there is evidence that the agent is asthmagenic; it is used in occupational settings; and it is available in Australia.

Results: The final list contained 277 asthmagens in 27 groups that may be found in occupational circumstances in Australia. Three other agents that have been documented as asthmagens in Australia were included: almond dust, fluoride (in aluminium pot room fumes);
\end{abstract} and sawdust from the Australian Blackwood.

Conclusions: This is the first comprehensive and inclusive list of Australian occupationally relevant asthmagens to have been compiled.

Implications: This list is specific for Australian workplace exposure to asthmagens. It will help focus policy and preventative practices and reduce the burden of occupational asthma. It will also be useful in future studies to identify those who are exposed to the asthmagens and provide information to assist regulators to identify industries, occupations, specific activities and existing exposure standards that can be targeted to improve worker health and welfare.

Key words: asthma, occupation, exposure

lists are available from bodies such as the National Industrial Chemicals Notification and Assessment Scheme (NICNAS), ${ }^{8}$ which is the Australian Government authority responsible for evaluating new and existing chemicals based on their health and environmental impacts, the Health and Safety Executive (HSE) in the UK and the Association of Occupational and Environmental Clinics (AOEC) in the US, not all of the listed asthmagens are related to occupation and, while some are encountered in Australia, others are not.

This paper describes how we have assembled a list of occupational asthmagens relevant to Australian workplaces. We limited our list to those asthmagens that are most relevant to working conditions in Australia. The aim is to provide a comprehensive catalogue of occupational asthmagens that may contribute to OA in Australia; it could be further used to focus policy and improve understanding of the extent of exposure.

\section{Methods}

For the purposes of this study, an asthmagen was defined as any substance that is causally related to the development or exacerbation of asthma symptoms. Occupational asthma was defined as"new-onset asthma in which the underlying cause is exposure to an asthmagen while at work".' OA excludes work-aggravated asthma, which is asthma

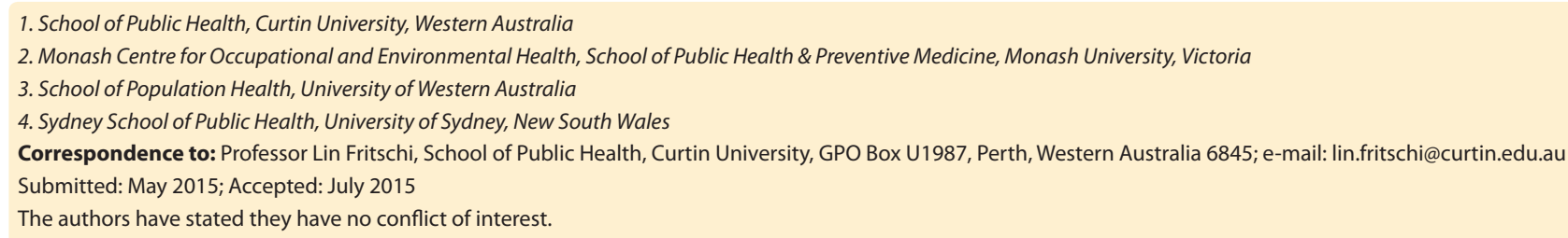


that occurs where workplace exposures provoke or exacerbate symptoms of existing asthma. OA can further be classified as sensitiser-induced or irritant-induced ${ }^{9}$ and most cases (about $90 \%$ ) of OA are sensitiserinduced. ${ }^{9}$ Sensitiser-induced asthma is characterised by the existence of a latency period between the first exposure to a respiratory sensitiser and the development of immunologically mediated symptoms, such as may be seen with latex exposures where the latency period maybe weeks or months..$^{10}$ Irritant-induced asthma typically occurs after months or years of exposure to a respiratory irritant, e.g. sulphur dioxide, chlorine or ammonia. This type of reaction is commonly associated with low molecular weight asthmagens such as diisocyanates or cyclic amines. Reactive airways dysfunction syndrome (RADS) is a subclass of irritantinduced asthma characterised by the sudden onset of asthma symptoms days after a single intense exposure to a respiratory irritant such as chlorine gas. ${ }^{11}$

Potential asthmagens that could be included in this list were identified through existing work health and safety classification databases in Australia and from a number of published articles by European, American or other agencies and professional associations. NICNAS 8 lists 108 agents that may cause serious irritation to the respiratory system based on observations in humans. The HSE 'Asthma Compendium' includes 45 substances as respiratory sensitisers. In the US, the AOEC has the largest and most comprehensive list of identified asthmagens and, as at March 2015, contains 438 occupationally related asthmagens. ${ }^{12}$ In addition, and most recently, Baur and Bakehe have published a wide-ranging review of 372 separate asthmagens. ${ }^{13}$ All the reference lists consulted had some asthmagens in common, although not all were work-related or encountered in Australia.

Our criteria for the inclusion of an agent to be selected for this asthmagen list were:

1. There is good evidence that the agent is asthmagenic.

2. The agent is used in occupational settings.

3. The agent is encountered in Australia.

\section{Evidence the agent is asthmagenic}

The absence of a routinely available test for asthma means that the available information for evaluating potential agents to induce asthma is largely based on clinical, incidental or epidemiological findings. Often clinical studies have focused on diagnosis of asthma in a patient, with identification of the asthmagen(s) being less specific or less clearly stated.

Almost all regulatory or other available lists of asthmagens focus on agents that are respiratory sensitisers and must be shown to induce respiratory hypersensitivity and subsequently trigger asthmatic episodes. However, the most extensive currently available list of asthmagens, produced by the US-based AOEC, includes agents designated as "sensitizing causes of asthma" and/or "non-sensitizing causes of asthma", which includes substances that cause RADS or irritant-induced asthma. We initially included all occupational asthmagens listed by AOEC. ${ }^{14}$ Additionally, we included all substances labelled according to the Australian Hazardous Substances Information System (HSIS) ${ }^{15}$ as either R37 "Substances which cause serious irritation of the respiratory system based on practical observations in humans or positive results from appropriate animal tests" or R42 "Substances which may cause sensitisation by inhalation, may induce specific respiratory hypersensitivity in the form of asthma based on human experience".

We added any agents labelled as H334 by the Globally Harmonised System for Classification and Labelling of Chemicals (GHS) that were not already included. The GHS is maintained by the European Chemicals Agency. ${ }^{16}$ The H334 label identifies agents that "may cause allergy or asthma symptoms or breathing difficulties if inhaled".

We then compared our list with recently published literature reviews of allergens causing $\mathrm{OA}$ by Chan-Yeung and Malo ${ }^{17}$ and by Baur and Bakehe. ${ }^{13}$

\section{Evidence the agent is used in occupational settings}

From the combined list of potential asthmagens and in consultation with occupational hygienists, we removed exposures not deemed to be primarily workrelated.

\section{Evidence the agent is used in Australia}

We consulted a number of data sources, including NICNAS, which maintains the Australian Inventory of Chemical Substances (AICS), listing data on chemicals manufactured or imported for use in Australia. In consultation with the occupational hygienists, any listed agents that were not likely to be found or permitted to be used in an Australian workplace were excluded.

\section{Results}

The AOEC list of 438 occupational asthmagens known to have a causal link to $O A^{12}$ was reduced to 309 agents by the removal of duplicate agents or agents listed under several common names, such as cutting oils, metal working fluids, and oil mist; and those agents that could be considered a sub-category of another agent. For example, sericin is a by-product of silkworms and is included under the silkworm listing, and carene is a constituent of turpentine and is included under the turpentine listing.

The only agent excluded as being nonoccupationally related was gluten, a dietary agent through which exposure occurs primarily by ingestion rather than through respiratory or dermal exposure.

A further 34 agents were considered unlikely to be encountered in Australia based on expert opinion, and included some arthropod species (specifically, screw worm fly and Mexican bean weevil), some specific wood dusts (i.e. those derived from iroko and kejaat tree species), and agents that are no longer in common use or not legally available in Australia such as enflurane, the explosive tetrazene, and medications such as diacetyl morphine.

We excluded carmine red dye (E120 food additive), as it is now banned in the US and rarely used in Australia. We also excluded Northern Hemisphere marine species such as the snow crab (Chineoecetes opililis), as this is not available in Australia, although Southern Hemisphere crabs were included (blue Swimmer crabs (Portunus pelagicus), giant mud crab (Scylla serrata) and spanner crabs (Ranina ranina)).

There were agents on the original lists to which occupational exposure is unlikely to be frequent (such as quillaja bark or isolyser). However, as there was limited information available about exposure prevalence, these agents have been included. The aim is to refine this list once more definitive exposure prevalence information becomes available.

The remaining 274 agents were then supplemented with three agents previously documented to cause OA in Australia, namely: almond dust; ${ }^{18}$ fluoride (as a constituent of 
Table 1: Twenty-seven groups of 277 occupational asthmagens.

$\begin{array}{ll}\text { Agent Group } & \text { Agen } \\ \text { 1. Arthropods or Mites } & \text { Acaria }\end{array}$

1. Arthropods or Mites

2. Acids

Acarian, Barn mite, Caddis flies, Cricket, Ephestia kuehniella (Mediterranean flour moth), Fowl mite, Fruit fly, Grain/Flour mites, Lesser mealworm, Locust, Mites NOS, Sheep blowfly, Silkworm Dodecanedioic acid, Glacial acetic acid, Hydrochloric acid, Peroxyacetic acid, Sulfuric acid/sulphor dioxide

3. Acrylates

4. Aldehydes

5. Amines

6. Ammonia

7. Anhydrides

8. Bio aerosols

9. Biological enzymes

10. Derived from animals

11. Derived from fish/shellfish

12. Derived from plants - othe

3. Epoxy

14. Ethylene oxide

15. Flour

16. Flowers

17. Foods

18. Industrial cleaning and sterilising agents

19. Isocyanates

21. Medications

22. Metals

24. Pesticides

26. Soldering fluxes

27. Wood dusts

Acrylic acid, Cyanoacrylates, NOS (glues), Methyl methacrylate, Polymethyl methacrylate (plexiglass), Trimethylolpropane triacrylate/2-Hydroxypropyl Acrylate

Formaldehyde, Gluteraldehyde, Paraformaldehyde, Urea formaldehyde

Aminoethyl ethanolamine, Diethanolamine, Dimethylethanolamine, Ethanolamines,

NOS, Ethylenediamine, Monoethanolamine, Surfactant-specific amines, Triethanolamine,

Triethylenetetramine, Trimethylhexane-1,6-diamine/Isophorondiamine mixture.

Anhydrous ammonia, Ammonium hydroxide, Ammonia solution 10\% and 29\%

Hexahydrophthalic anhydride, Himic anhydride, Maleic anhydride, Methyl tetrahydrophthalic anhydride, Phthalic anhydride, Tetrachlorophthalic anhydride, Trimellitic anhydride

Alternaria, Chrysonilia sitophilia, Neurospora, Penicillium, Cutting oils

Bacillus subtilis enzymes, Bromelain, Egg lysozyme, Esperase, Flaviastase, Fungal amylase, Fungal amyloglucosidase, Fungal hemicellulose, Pancreatin, Papain, Pepsin, Trypsin

Bat guano, Bovine serum albumin, Casein, Cat, Chicken, Cow dander, Frog, Guinea Pig antigens, Lactoserum, Mice, Pig, Rabbit antigens, Rat antigens

Anisakis simplex (herring worm), Clam, Crab, Cuttlefish, Fish feed, Nacre dust, Octopus, Prawn, Red soft coral, Salmon, Shrimp meal, Trout

Almond dust, Arabidopsis thaliana, Chlorella algae, Grain dust, Gum Arabic, Henna, Kapok, Linseed oilcake, Pinellia ternate, Quillaja bark, rice dust, Tall oil crude, Tall oil - Rosin, Tobacco leaf, Tragacanth, Turpentine, Vicia sativa (vetch), Weeping fig.

\section{Adhesive, Epoxy}

Ethylene oxide

Buckwheat, Flour NOS, Rye flour, Soya flour, Wheat flour

Baby's breath, Freesia, Limonium tataricum, Sunflower

Brazil ginseng, Castor bean, Chamomile, Cinnamon, Dioscorea batatas (Chinese yam), Egg protein, Fenugreek, Garlic dust, Green beans, Guar, Hops, Paprika, Pectin, Rose hips, Soybean lecithin, Tea, Thiamine (vitamin B), Thyme

Alkyl dimethyl benzyl ammonium chloride, Benzyl-C10-16-alkyldimethyl, chlorides, Benzyl-C1216-alkyldimethyl, chlorides, Benzyl-C12-18-alkyldimethyl, chlorides, Benzyl-C16-18-alkyldimethyl, chlorides, Benzyldimethylstearyl ammonium chloride, BTC 776, BTC 927, Cetalkonium chloride, Chlorhexidine, Chlorine, Dialkyl methyl benzyl ammonium chloride, Dicumyl-peroxide, Didecyl dimethyl ammonium chloride, Dimethyl ethyl benzyl ammonium chloride, Dodecyl-dimethylbenzylammonium, Fluorine, Persulphate salts, Quarternary ammonium compounds NOS, Sodium hypochlorite, Sodium metabisulfite

Diisocyanates, NOS, HDI Prepolymers, Hexamethylene diisocyanate HDI, Isophorone diisocyanate, Methylene bisphenyl diisocyanate, Naphthalene diisocyanate NDI, Polymethylene polyphenylisocyanate, TDI Prepolymers, Toluene diisocyanate

Latex, natural rubber

Ampicillin, Amprolium, Cimetidine, Codeine, Colistin, Hydralazine, Ipecacuanha, Hydrocodone, Isonicotinic acid hydrazide, Methyldopa, Morphine, Opiate compounds, Oxycodone, Papaverine, Penicillamine, Penicillins, Phenylglycine acid chloride, Psyllium, Salbutamol intermediate, Spiramycin, Tetracycline, Thebaine, Tylosin tartrate, Vancomycin

Aluminium, Aluminium chloride, Aluminium oxide, Aluminium compounds, Ammonium dichromate or hexachloroplatinate (IV), Chromium NOS, metal, hexavalent and, non-hexavalent, Cobalt, Cobalt compounds, Gas metal arc welding on uncoated mild steel, Nickel, Nickel compounds, Platinum, Rhodium, Soluble halogenated platinum compounds NOS, Titanium oxide/dioxide, Tributyl tin oxide, Tungsten carbide, Tungsten carbide/cobalt, Vanadium, Welding fume, stainless steel, Zinc oxide

23. Other reactive chemicals Fluoride, Freon heated, Furfuryl alcohol mixed with a catalyst, Isolyzer, Polyethylene terephthalate/ Polybutylene terephthal, Polyfunctional Aziridine (PFA), Polypropylene heated, Polyvinyl chloride heated or non-heated or thermal decomposition, Radiographic fixative, Resin containing furfuryl alcohol, Styrene, Trigylicidyl isocyanurate

3-Amino-5-mercapto-1,2,4-triazole, Acephate, Chloramine T, Chlorothalonil (Bravo, Echo), Diazinon, Dimethoate, Fenthion, Malathion, Nemacur, Piperazine, Piperazine citrate, Piperazine hydrochloride, Pyrethrins, Pyrfon, Safrotin, Tetramethrin

25. Reactive dyes Cibachrome Brilliant Scarlet 32, Drimarene Brilliant Blue K-BL, Drimarene Brilliant Yellow K-3GL, Lanasol Yellow 4G, Levafix Brilliant Yellow E36, Methyl Blue, Reactive Dyes, NOS, Rifacion Orange HE 2G, Rifafix Yellow 3 RN, Rifazol Black GR, Rifazol Brilliant Orange 3R

Colophony, soldering flux (heated) Alkyl aryl polyether or Zinc

African Maple (Triplochiton scleroxylon), Blackwood (Acacia melanoxylon), California Redwood (Sequoia sempervirens), Central American Walnut (Juglans olanchana), Eastern White Cedar (Thuja occidentalis), Mahogany (Shoreal sp.), Oak (Quercus robur), Western Red Cedar (Thuja Ipicata). aluminium pot room fumes); ${ }^{19}$ and sawdust from the Australian Blackwood (Acacia melanoxylon) timber. ${ }^{20}$

The final list of 277 agents was categorised into 27 occupationally associated groups (following the groupings used by Kennedy et al.) ${ }^{21}$ Two asthmagens, latex and ethylene oxide, were identified as stand-alone specific agents. Other groups included isocyanates $(n=9)$, pesticides $(n=21)$ and metals $(n=22)$. The complete list of 277 occupational asthmagens in 27 groups is in Table 1.

\section{Discussion and conclusions}

The aim of this project was to assemble a comprehensive list of substances that may be encountered in an Australian workplace and for which there is good evidence they can lead to the development of OA. To limit or prevent $\mathrm{OA}$, it is important to understand which asthmagens are encountered in the workplace. Our final list contained 277 known or probable occupational asthmagens separated into 27 groups. This list was designed to be broad and inclusive, and therefore should enable a wide range of research and policy aims to be met.

The list will permit the future estimation of the number of Australian workers who may be exposed to asthmagens at work. It will help to identify industries and occupations with a high prevalence of exposure to asthmagens and, therefore, where occupational health and safety interventions can be targeted to have the greatest effect. The process followed in establishing this list was transparent and reproducible, and could be used in establishing similar lists for other disease outcomes and in other countries.

Our list was closely aligned with the Canadian list prepared by Chan-Yeung and Malo ${ }^{17}$ but omitted agents such as tetrazene, some medications, several non-Australian arthropods and 12 types of wood or timber not available in Australia. Our metal group was more extensive and included aluminium, rhodium, titanium, tin and vanadium not mentioned by Chan-Yeung et al.

A number of factors limited the collation of an Australian specific list of occupational asthmagens. The information sources and the breadth and depth of information available for each of the listed agents varied. Estimates of the nature and extent of exposures to workplace hazards may be based on data derived from self-reported information about workplace exposures. 
The 2008 National Hazard Exposure Worker Surveillance (NHEWS) survey is an example of this approach. ${ }^{22}$ However, the NHEWS survey provided limited information on specific asthmagens, because it relied on respondents being able to identify the agents that may have been contained in chemical fumes or dusts that they were exposed to. NHEWS did not collect information on exposures to a range of non-chemical and biological asthmagens, such as occurs with pot room fumes in aluminium smelting plants ${ }^{19}$ or mouse urine in animal cages.

The specific asthmagenic agents are difficult to identify in such circumstances. High quality studies of prevalence of exposure are rare and available reports are often case studies of affected individuals. Prevalence studies may underestimate exposure because of the Heathy Worker Effect where individuals affected by asthma symptoms may choose to work in jobs in which the potential for asthmagen exposure is low; they may be excluded from being hired; or they may seek transfer to less exposed jobs or leave that workplace. ${ }^{23}$ The list will help future researchers identify workplaces where low prevalence of asthma is observed due to the presence of identified asthmagens.

A high-quality survey of prevalence of exposure to occupational asthmagens is now needed in Australian workplaces.

\section{Implications}

We have collated a practical and relevant list of occupationally related asthmagens, which is inclusive and relevant for Australian workplaces. This list will permit regulators to identify industries, occupations, specific activities and existing exposure standards that can be targeted to improve worker health and welfare. This list could form the foundation of future studies to better describe and understand the extent of exposure to occupational asthmagens in
Australia and, in particular, to identify those occupations where the greatest number of workers are at risk of exposure and also where exposure to asthmagens is most likely to occur. The list would also be useful as a reference for medical or occupational health and safety organisations that currently have no comprehensive reference list to refer to when considering a diagnosis of $O A$.

\section{Acknowledgements}

This study was funded by the National Health and Medical Research Council (\# 1056684) and Safe Work Australia. We acknowledge gratefully the advice provided by: $\mathrm{Dr}$ Jonathan Burdon, respiratory physician and director of the National Asthma Council of Australia; Dr Ryan Hoy, respiratory physician and research fellow at Monash Centre for Occupational and Environmental Health; Dr Jan-Paul Zock, Netherlands Institute for Health Services Research and Centre for Research in Environmental Epidemiology; Associate Professor Jeremy Beach, School of Public Health, University of Alberta, Canada; Sandy Ashton, senior strategy officer, Prevention Strategy Division, WorkSafe Victoria; Dr Jenny Job and Brett Bissett at Safe Work Australia.

\section{References}

1. Australian Institute of Health and Welfare. Australian Centre for Asthma Monitoring 2008. Asthma in Australia. Canberra (AUST): AlHW, 2008.

2. Johnson A, Toelle BG, Yates $D$, et al. Occupational asthma in New South Wales (NSW): A population-based study. Occup Med (Oxford). 2006;56:258-62.

3. Toren K, Blanc PD. Asthma caused by occupational exposures is common- a systematic analysis of estimates of the population-attributable fraction. $B M C$ Pulm Med. 2009;9:7.

4. Anderson NJ, Fan ZJ, Reeb-Whitaker C, et al. Distribution of asthma by occupation:Washington State behavioral risk factor surveillance system data, 2006-2009. J Asthma. 2014;51(10):1035-42.

5. Hannaford-Turner K, Elder D, Sim MR, et al. Surveillance of Australian workplace based respiratory events (SABRE) in New South Wales. Occup Med (Oxford). 2010;60:376-82.
6. Elder D, Abramson M, Fish D, et al. Surveillance of Australian workplace based respiratory events (SABRE): Notifications for the first 3.5 years and validation of occupational asthma cases. Occup Med (Oxford). 2004;54:395-9.

7. Hoy RF, Abramson MJ, Sim MR. Work related asthma diagnosis and management. Aust Fam Physician. 2010;39:39-42

8. National Industrial Chemicals Notification and Assessment Scheme. About NICNAS. Sydney (AUST): Commonwealth of Australia; 2010.

9. Nicholson PJ, Cullinan P, Newman Taylor AJ, et al. Evidence based guidelines for the prevention, identification, and management of occupational asthma. J Occup Environ Med. 2005;62:290-9.

10. Hoy RF, Burgess JA, Benke G, et al. Occupational exposures and the development of new-onset asthma: A population-based cohort study from the ages of 13 to 44 years. J Occup Environ Med. 2013;55:235-9.

11. Henneberger PK, Derk SJ, Davis L, et al. Work-related reactive airways dysfunction syndrome cases from surveillance in selected US States.J Occup Environ Med. 2003;45:360-8.

12. Association of Occupational and Environmental Clinics, Revised Protocol: Criteria for Designating Substances as Occupational Asthmagens on the AOEC List of Exposure Codes. Washington (DC): AOEC; 2008

13. Baur $X$, Bakehe P. Allergens causing occupational asthma: An evidence-based evaluation of the literature. Int Arch Occup Environ Health. 2014;87:339-63.

14. Beckett W. Revised Protocol: Criteria for Designating Substances as Occupational Asthmagens on the AOEC List of Exposure Codes. Washington (DC): AOEC; 2008.

15. SafeWork Australia. Hazardous Substances Information System (HSIS). Canberra (AUST): Commonwealth of Australia; 2014

16. Safe Work Australia. GHS Hazardous Chemical List Canberra (AUST): Commonwealth of Australia; 2014.

17. Chan-Yeung M, Malo J. Aetiological agents in occupational asthma. Eur Respir J. 1994;7:346-71.

18. Foti $C$, Nettis E, Cassano N, et al. Non-allergic occupational asthma because of almond shell dust. Allergy. 2008;63:1087-8.

19. Abramson MJ, Benke GP, Cui JS, et al. Is potroom asthma due more to sulphur dioxide than fluoride? An inception cohort study in the Australian aluminium industry. J Occup Environ Med. 2010;67:679-85.

20. Wood-Baker R, Markos J. Occupational asthma due to blackwood (Acacia melanoxylon). Aust N Z J Med. 1999;27:452-3.

21. Kennedy SM, LeMoual N, ChoudatD, et al. Development of an asthma specific job exposure matrix and its application in the epidemiological study of genetics and environment in asthma (EGEA). J Occup Environ Med. 2000;57:635-41.

22. Australian Safety and Compensation Council.National Hazard Exposure Worker Surveillance (NHEWS) Survey. Canberra (ASUT): Commonwealth of Australia; 2009.

23. Le Moual N, Kauffmann F, Eisen EA, et al. The healthy worker effect in asthma. Am J Resp Crit Care. 2008;177: 4-10. 